\title{
ARTIGOS
}

\section{Evolução das despesas da função desporto e lazer (FDL) dos municípios do estado do Piauí de 2003 a 2011}

\section{RESUMO}

\author{
Edmilson Santos dos Santos \\ Fernando Augusto Starepravo² \\ Felipe $\mathrm{Canan}^{3}$
}

A literatura sobre financiamento de políticas públicas de esporte e lazer tem centrado sua atenção nos investimentos do Governo Federal, deixando uma lacuna sobre análises de âmbito municipal. O objetivo do presente trabalho foi analisar o comportamento dos municípios do estado do Piauí no período de 10 anos (2003 a 2012), no que se refere aos investimentos nas políticas públicas de esporte e de lazer. As informações referentes à receita corrente e às despesas na FDL foram retiradas diretamente dos dados referentes às contas anuais no site Sistema de Informações Contábeis e Fiscais do Setor Público Brasileiro - Siconfi. Os resultados apontam que os municípios do Piauí tiveram crescimento em suas receitas correntes, nominal e per capita. Mesmo reconhecendo que o crescimento da receita não leva, necessariamente, ao crescimento nos mesmos índices das despesas, tendo em vista que os recursos são sempre escassos e disputados, a FDL teve crescimento importante do ponto de vista nominal e quando comparado com a receita. Conclui-se que há um ambiente propício a garantir investimentos no esporte e no lazer em âmbito municipal no estado do Piauí.

Palavras-chave: Políticas públicas. Descentralização. Financiamento. Esporte. Lazer.

1 Doutor em Ciências do Movimento Humano. Professor da Universidade Federal do Vale do São Francisco (UNIVASF). Petrolina/Pernambuco, Brasil. E-mail: edmilson.santos@univasf.edu.br

2 Doutor em Educação Física. Professor da Universidade Estadual de Maringá (UEM). Maringá/Paraná, Brasil. E-mail: fernando.starepravo@hotmail.com

3 Doutorando em Educação Física. Professor da Universidade Estadual do Oeste do Paraná (UNIOESTE). Marechal Cândido Rondon/Paraná, Brasil. E-mail: felipe.canan@gmail.com 
Evolution of SLF expenses of municipalities in Piauí from 2003 to 2011

\begin{abstract}
The literature on the financing of public policies for sports and leisure has focused its attention on the investments of the Federal Government, leaving a gap on analyzes of municipal scope. Its aim was to analyze the behavior of municipalities from the state of Piauí in a 10-year time span (from 2003 to 2012), regarding investments in public policies in sport and leisure. As it could have been noticed along this study, municipalities in Piauí have had growths in their current, nominal and per capita revenue. However, revenue growth does not necessarily lead to growth in expenses indexes, bearing in mind that resources are always rare and disputed. SLF has had important growth, though, from the nominal point of view, when compared to the revenue. There is a much more favorable environment to guarantee investments in sport and leisure in a municipal level.
\end{abstract}

Keywords: Public policies. Decentralization. Funding. Sport. Leisure.

Evolución de los gastos en la FDL de municipios en el estado de Piauí entre 2003 y 2011

\title{
RESUMEN
}

La literatura sobre las políticas de financiación del deporte y el ocio se ha centrado la atención en la inversión del Gobierno Federal, dejando una brecha en el análisis a nivel municipal. El objetivo fue analizar el comportamiento de los municipios del estado de Piauí el período de 10 años (2003-2012), con respecto a las inversiones en las políticas públicas para el deporte y el ocio. Como puede verse en toda la obra, los municipios de Piauí tuvieron un crecimiento en sus fuentes de ingresos, nominal y per cápita. Sin embargo, el crecimiento de ingresos no necesariamente conduce al crecimiento en mismas tasas de gasto, dado que los recursos son siempre escasos y disputados. Pero el FDL tuvo un crecimiento significativo en el punto de vista nominal y comparado con la receta. Hay un contexto muy propicio para garantizar la inversión en el deporte y la recreación en el entorno municipal.

Palabras clave: Políticas públicas. La descentralización. Financiación. Deporte. Ocio. 


\section{INTRODUÇÃO}

O esporte e o lazer são objetos de atenção do Estado brasileiro, ao menos desde a década de 1940, quando por meio da ação legislativa, o Estado brasileiro passou a controlar e financiar ações relativas ao esporte e lazer (MORAES E SILVA et al, 2016). Desde então, inúmeras políticas públicas de esporte e lazer foram desenvolvidas, primeiramente pelo governo federal, e mais tarde por estados e municípios. A literatura especializada (LINHALES, 1996; MORAES E SILVA et al, 2016; STAREPRAVO, 2011; VERONEZ, 2005) apontam como marcos da trajetória estatal do esporte no Brasil: a Constituição Federal de 1988 (CF 88), que garantiu a volta da autonomia ao campo esportivo e o reconhecimento do esporte e lazer como direitos; e, em 2003, a criação do Ministério do Esporte que garantiu, naquele momento, pela primeira vez na história, que o esporte fosse tratado como objeto de intervenção do Estado brasileiro em nível de primeiro escalão, em um Ministério exclusivo.

A autonomia política dos entes federados, aliado a obrigação do poder público em promover o esporte e o lazer (BRASIL, 1988), parece ter estimulado estados e municípios a implementarem políticas públicas de esporte e lazer. Ao buscar desvelar a atuação do poder público municipal no esporte e lazer, o olhar sobre o orçamento público destinado ao esporte e lazer parece ser um caminho possível e promissor.

Destaca-se que, nos debates públicos instalados no Brasil pós-2003, no aspecto mais geral da política, se destaca o papel das Conferências no estabelecimento de um canal condutor entre as demandas da população e a agenda de governo. Houve uma expectativa de que elas pudessem ser capazes de traduzir a percepção média dos atores interessados nas diferentes temáticas discutidas.

No âmbito do esporte e lazer, a primeira Conferência Nacional de Esporte aconteceu em 2004 (MINISTÉRIO DO ESPORTE, 2004), após rodadas municipais e estaduais de discussões. A Conferência acabou trazendo à tona o debate de algumas questões intrigantes sobre a gestão do esporte e seu financiamento. A primeira observação diz respeito à necessidade de promover a democratização das políticas públicas de esporte e de lazer; outra diz respeito à necessidade de estabelecer patamares mínimos para investimentos nas políticas públicas de esporte e de lazer.

Além de apontar para a necessidade de um Sistema Nacional de Esporte, a Conferência sinalizou alguns princípios, diretrizes e objetivos importantes. Houve deliberações na direção: (a) do reconhecimento do esporte e lazer como direitos sociais, ratificando o artigo $6^{\circ}$ e interpretando/complementando o artigo 217 da Constituição Federal (CF) (BRASIL, 1988), que preveem, respectivamente, o lazer como direito social e o esporte como direito de cada um; (b) da necessidade de descentralização das políticas públicas de esporte e de lazer; (c) da garantia de dotação orçamentária de no mínimo 1\% à pasta do esporte e lazer. A segunda Conferência Nacional de Esporte (BRASIL, 2006) reproduziu, em boa medida, as preocupações explícitas na $1^{\text {a }}$ Conferência no que diz respeito à descentralização e à necessidade de melhorar o financiamento das políticas de esporte e de lazer. 
Apesar das rodadas municipais, houve uma lacuna informacional que impediu conhecer a realidade da participação dos municípios no financiamento das políticas de esporte e de lazer no Brasil. Desde 2002, o governo federal disponibiliza informações sobre as despesas dos municípios brasileiros, inclusive as referentes à Função Desporto e Lazer (FDL), através do Sistema de Informações Contábeis e Fiscais do Setor Público Brasileiro - Siconfi (TESOURO NACIONAL, 2016). Ao final do exercício fiscal, os municípios cadastram os gastos realizados nas políticas de esporte e de lazer em quatro subfunções: desporto comunitário, desporto de rendimento, lazer, e demais subfunções do esporte e lazer. O somatório dos gastos das quatro subfunções fica cadastrado como despesas na FDL.

Em 2002, por exemplo, 78,61\% ( $=4.375)$ municípios brasileiros fizeram investimentos na FDL. Mesmo numa métrica estreita sobre a democratização das políticas públicas de esporte e de lazer, deve-se reconhecer que atingir esse número aponta, no mínimo, uma descentralização já consolidada ou em processo. Os valores envolvidos não são desprezíveis, totalizando $\mathrm{R} \$$ 1.038.339.865,34. Para se ter ideia da quantidade de recursos disponibilizados pelos municípios, em um único ano ela representou, comparativamente, 93,65\% do que foi liquidado pelo Programa Segundo Tempo (PST) ${ }^{4}$ de 2004 a 2011 (CASTRO, 2016, p. 277).

Em 2003, o valor investido pelos municípios na FDL passou para $\mathrm{R} \$ 1.112 .166 .458,82$, o que representa um crescimento de $7,11 \%$ em relação a 2002. Em termos de participação dos municípios, isso significou um avanço de 1,89\%, uma vez que em 20044.458 municípios investiram na FDL.

Ao discutir a produção de conhecimento sobre as políticas públicas de esporte e lazer, Starepravo (2013) destaca que a produção científico/acadêmica no Brasil é recente e repleta de lacunas. Apesar do número crescente de pesquisadores envolvidos com o estudo das políticas públicas de esporte e lazer, estes privilegiam os estudos da atuação do governo federal por meio de importantes programas, como o PST, o Programa Esporte e Lazer da Cidade (PELC) e o Programa Bolsa-atleta. Observa-se, neste sentido, uma importante lacuna nos estudos das políticas públicas municipais de esporte e lazer (STAREPRAVO, 2013).

Além disso, são poucos os trabalhos dedicados ao estudo do orçamento destinado a esta área, exceção aos estudos de Almeida e Marchi Jr. (2010), que analisaram os repasses do governo federal; Athayde, Mascarenhas e Salvador (2015), que analisaram o financiamento do esporte educacional e esporte de participação durante o Governo Lula; Teixeira, Matias e Mascarenhas (2013), que analisaram o financiamento do governo federal para realização dos Jogos Olímpicos e Paralímpicos de 2016; Figuerôa et al. (2014) que teceram críticas sobre o financiamento do esporte de rendimento no Brasil; e mais recentemente Castro (2016), que analisou o planejamento e execução orçamentária do governo federal de 2004 a 2011. Todos os trabalhos citados acima, porém, não apresentam como lócus de

4 O Programa, promovido pelo Ministério do Esporte, é implementado pelos entes subnacionais (governos estaduais e municipais), terceiro setor (pelo menos até 2010) e determinados órgãos federais. O programa tem como objetivo principal "democratizar o acesso à prática e à cultura do Esporte de forma a promover o desenvolvimento integral de crianças, adolescentes e jovens, como fator de formação da cidadania e melhoria da qualidade de vida, prioritariamente em áreas de vulnerabilidade social" (MINISTÉRIO do ESPORTE, 2015). 
estudo o contexto municipal. Há poucos estudos que apresentam análises sobre recursos financeiros destinados aos órgãos municipais de esporte (GALINDO, 2005; MEZZADRI et al, 2006; MENEZES; OLIVEIRA; SOUZA, 2012; SILVA; COUTO; SANTOS, 2014).

Considerando estes apontamentos introdutórios percebe-se que há um longo caminho para se percorrer no campo da análise do financiamento do esporte e do lazer por parte dos municípios brasileiros. Considerando a lacuna científico-acadêmica sobre o financiamento público municipal do esporte e lazer, e a reinvindicação da comunidade esportiva, por meio das Conferências Nacionais de Esporte, de maiores investimentos públicos no esporte e lazer, o presente trabalho surgiu com objetivo de avaliar a evolução da participação dos municípios do estado do Piauí ${ }^{5}$ no investimento na Função Desporto e Lazer.

\section{METODOLOGIA}

O presente estudo, de natureza descritiva, buscou analisar o comportamento dos municípios do estado do Piauí no período de 10 anos (2003 a 2012), no que se refere aos investimentos nas políticas públicas de esporte e de lazer. Para tanto, estabeleceu-se dois procedimentos principais:

a) Identificar o comportamento nominal ${ }^{6}$ e per capita da receita corrente dos municípios de 2003 a 2012 por classe populacional. A título de esclarecimento, "receita corrente" traduz-se pelo patrimônio não duradouro do Estado, ou seja, aquele que se esgota dentro do período anual (TESOURO NACIONAL, 2016).

b) Verificar o comportamento do investimento corrente per capita dos municípios na FDL, de 2003 a 2012, por classe populacional.

As informações referentes à receita corrente e às despesas (no estudo descrito como investimento) na FDL foram retiradas diretamente dos dados referentes às contas anuais no site Sistema de Informações Contábeis e Fiscais do Setor Público Brasileiro - Siconfi (TESOURO NACIONAL, 2016). Destaca-se que o Siconfi é uma importante e confiável base de dados para o acompanhamento e estudo dos gastos públicos, disponível à população através de um portal online e de livre acesso.

Para informações referentes à classe populacional (CP) foi utilizada como referência a distribuição por classe populacional do Instituto Brasileiro de Geografia e Estatística (IBGE, 2016). O estudo acompanhou as três primeiras classes populacionais do IBGE (CP1, até 5.000 habitantes; CP2 de 5.001 a 10.000 habitantes; CP3 de 10.001 a 20.000 habitantes) e, tendo em vista o menor " $n$ " de municípios acima de 20.000 habitantes, estes foram organizados em apenas mais dois níveis: CP4, de 20.001 a 50.000 habitantes; e CP5, acima de 50.001 habitantes $^{7}$.

5 O Piauí é um dos 26 estados brasileiros. Possui uma população estimada pelo IBGE, em 2016, de 3.212.180 pessoas, e é formado por 224 municípios.

6 O estudo não realizou nenhum índice de correção dos valores, eles correspondem aos valores de face.

7 A decisão de aglutinar todas as cidades acima de 50.000 habitantes em apenas uma classe populacional se deve ao fato de que elas representam parcela muito pequena dos municípios da Paraíba ( $\mathrm{n}=5$ ): Floriano (57.690 hab.), Piripiri (61.834 hab.), Picos (73.414 hab.), Parnaíba (145.705hab.) e Teresina (814.230 hab.). 
As informações per capita foram obtidas com base no número de habitantes que consta na planilha de dados do Siconfi. Os dados compuseram uma planilha contendo o nome dos municípios do estado do Piauí, a população e as informações fiscais (receitas e despesas) (TESOURO NACIONAL, 2016).

Todas as coletas de dados, no site do Tesouro Nacional e do IBGE, foram realizadas entre os dias 01 e 11 de dezembro de 2016 e utilizou-se a estatística descritiva para a caracterização dos cenários.

\section{FINANÇAS MUNICIPAIS}

A centralização decisória e o financiamento das políticas públicas na mão do governo central durante a Ditadura Militar fez surgir forte pressão municipalista durante a Assembleia Nacional Constituinte de 1987-88. A descentralização da política e de recursos era percebida como um vetor de democratização da sociedade brasileira. Foi esse contexto que fez inaugurar a primeira federação que alçou a posição de ente federado à municipalidade. O Brasil é a única dentre as 28 federações do mundo com três entes federados (União, estados e Distrito Federal e municípios). Como destaca Afonso (2003), foram as circunstâncias políticas que tornaram a descentralização uma realidade.

Como ente federado, foi garantido aos municípios autonomia para decidir as meIhores políticas à comunidade local. Desde a CF 88, tem-se realizado periodicamente as eleições municipais, o que tem garantido estabilidade à gestão das prefeituras. Foi garantida também relativa autonomia fiscal aos municípios, já que as prefeituras podem legislar sobre três impostos que são importantes para o financiamento de políticas públicas (Imposto Predial e Territorial Urbano - IPTU, Imposto de Transmissão de Bens Imóveis - ITBI e Imposto Sobre Serviços de Qualquer Natureza - ISS). Além desses recursos, há as transferências constitucionais obrigatórias que estão fora do alcance da negociação política: cota parte do Fundo de Participação dos Municípios (FPM), que é redistributiva [fonte principal de financiamento para muitas prefeituras (BOVO, 2001)] por parte do governo federal, e cota parte do Imposto sobre Circulação de Mercadoria e Serviços (ICMS), que é devolutiva por parte dos estados aos municípios.

No entanto, as desigualdades quanto à urbanização dos municípios, déficit de políticas públicas, cultura política local (pressão clientelista), qualificação da burocracia, recursos administrativos para o uso eficiente dos recursos, dinâmica econômica local, nível de desenvolvimento humano, por exemplo, produziram um cenário de elevada assimetria no financiamento de políticas públicas (REZENDE; SLOMSKI; CORRAR, 2005; BREMAEKER, 1994).

Silva, Couto e Santos (2014) realizaram uma análise sobre a estrutura administrativa e financeira do esporte no município de Ipiaú, estado da Bahia. Os autores apontam a ausência de política pública significativa no município, considerando que as ações que são implementadas visam apenas suprir exclusivamente as demandas momentâneas do município. Em relação às questões financeiras, relatam que os recursos são destinados à construção e reforma de infraestrutura e apoio a eventos pontuais. Dessa forma, mesmo reconhecendo que houve crescimento no volume de aporte financeiro para os municípios desde a redemocratização 
(AFONSO, 2003; BOVO, 2001; AFONSO et al, 1998), ainda restam problemas de gestão eficiente dos recursos públicos, fator que acaba promovendo mais desigualdades entre os municípios (MOTTA; MOREIRA, 2007), inclusive quando se trata da própria descentralização de recursos federais como produtora de mais desigualdade (GOMES; DOWELL, 2000).

A CF 88 deixou brechas no que diz respeito à descentralização de encargos, principalmente sobre as políticas sociais. No que concerne à saúde e à educação, esse processo sofreu um longo ajuste político-legislativo até estabelecer as obrigações dos municípios com relação ao financiamento e aos serviços que devem ser oferecidos nestas áreas. Em outras áreas prevalece processo desordenado de descentralização dos encargos (AFONSO et al., 2000).

Na área esportiva há razões institucionais para esse "desordenamento". O primeiro, e principal argumento, é que pós-CF 88 não foram produzidas normas capazes de orientar o comportamento dos atores federados, o que, talvez, na lógica da concorrência por oferta de serviços, não fosse necessário. Ao estabelecer o esporte como área de competência comum, mesmo que apenas legislativa (Inciso IX do Art. 24 da CF) (BRASIL, 1988), os constituintes confiavam que nas áreas de maior demanda da população os atores políticos institucionais (prefeitos e vereadores) iriam promover uma corrida em busca de accountability. Porém, Mezzadri et al (2006), ao analisarem as políticas públicas de esporte e lazer quinze municípios do estado do Paraná, observaram problemas relacionados à falta de planejamento, recursos humanos e dificuldades orçamentárias em cidades de grande porte e as localizadas no litoral daquele estado.

Na área esportiva houve, diante da falta de políticas públicas no nível federal até a criação do Ministério do Esporte em 2003, uma sinalização de que havia paralisia política na oferta de políticas públicas de esporte e de lazer.

Passados mais de dez anos de implementação de políticas de esporte e de lazer por parte do Ministério do Esporte, nem a tão esperada descentralização de suas políticas aconteceram de forma a democratizar o PST e o PELC, por exemplo, que são dois dos principais Programas Federais, que ideologicamente se pretendem democráticos e descentralizados, nem os municípios se mantiveram apáticos em relação a essa realidade. Souza Neto, Santos e Starepravo (2015), por exemplo, observaram um vazio assistencial do PST na região Nordeste do Brasil. Nesse caso, compreender melhor a relação entre políticas públicas de esporte e de lazer e seu financiamento por parte dos municípios torna-se fundamental para se conhecer os investimentos nessa seara.

\section{ANÁLISE DOS RESULTADOS}

A análise dos resultados se fará de forma a permitir a avaliação da receita corrente, nominal e variação percentual no período, e, num segundo momento, dos investimentos na FDL. Posteriormente, a análise comparativa entre a variação do comportamento da receita corrente e do investimento na FDL permitirá compreender como as prefeituras têm respondido frente às políticas públicas de esporte e lazer. 


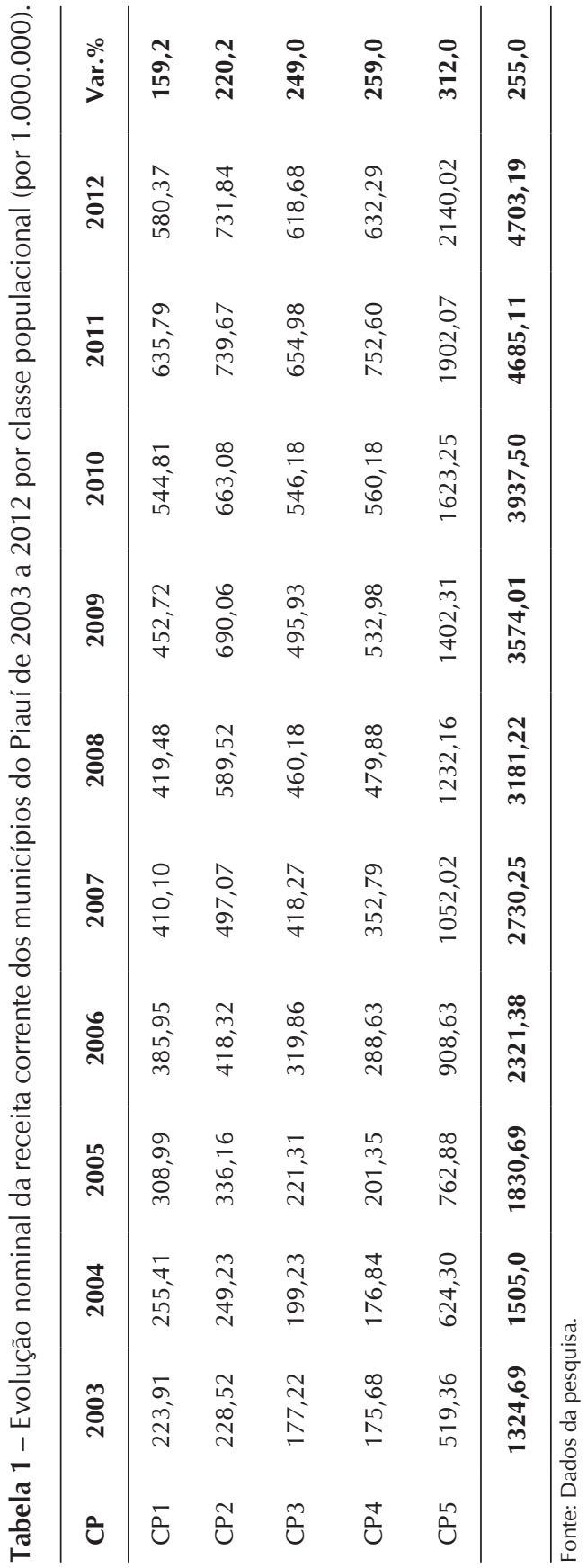


No período que vai de 2003 a 2012 houve variação importante na receita corrente dos municípios do Piauí. Em dez anos o incremento das receitas foi superior a $255 \%$. Como pode ser observado, essa variação foi positiva para todas as classes populacionais, sendo que a menor variação ficou com as cidades até 5.000 habitantes (CP1).

No entanto, como pode ser percebido na Tabela 1, apenas duas classes populacionais tiveram crescimento acima da média, CP4 e CP5. Ou seja, apesar da variação positiva em todas as classes, somente as cidades acima de 20.000 habitantes experimentaram crescimento nominal maior. A maior variação se deu, inclusive, nas cidades com mais de 50.000 habitantes. Nesse sentido, o aumento da receita segue pari passu ao maior contingente populacional dos municípios e, portanto, sua maior taxa de urbanização.

Tabela 2 - Evolução da receita corrente per capita média dos municípios do Piauí de 2003 a 2012 por classe de população (por 1.000).

\begin{tabular}{llllllllllll}
\hline CP & $\mathbf{2 0 0 3}$ & $\mathbf{2 0 0 4}$ & $\mathbf{2 0 0 5}$ & $\mathbf{2 0 0 6}$ & $\mathbf{2 0 0 7}$ & $\mathbf{2 0 0 8}$ & $\mathbf{2 0 0 9}$ & $\mathbf{2 0 1 0}$ & $\mathbf{2 0 1 1}$ & $\mathbf{2 0 1 2}$ & Var.\% \\
\hline CP1 & 0,729 & 0,863 & 1,088 & 1,230 & 1,420 & 1,648 & 1,694 & 1,856 & 2,264 & 2,359 & $\mathbf{0 , 2 2 3}$ \\
CP2 & 0,475 & 0,572 & 0,709 & 0,785 & 0,952 & 1,116 & 1,181 & 1,274 & 1,571 & 1,681 & $\mathbf{0 , 2 5 4}$ \\
CP3 & 0,414 & 0,500 & 0,607 & 0,684 & 0,794 & 0,978 & 1,039 & 1,191 & 1,382 & 1,619 & $\mathbf{0 , 2 9 1}$ \\
CP4 & 0,335 & 0,391 & 0,489 & 0,536 & 0,653 & 0,784 & 0,863 & 0,969 & 1,220 & 1,288 & $\mathbf{0 , 2 8 4}$ \\
CP5 & 0,361 & 0,449 & 0,549 & 0,636 & 0,798 & 0,905 & 1,051 & 1,180 & 1,377 & 1,525 & $\mathbf{0 , 3 2 3}$ \\
\hline
\end{tabular}

Fonte: Dados da pesquisa.

A receita corrente per capita também variou no período. Assim como aconteceu com a receita nominal, o crescimento foi mais robusto na maior classe populacional. Chama atenção o crescimento na CP5 ter sido superior a todas as outras classes populacionais. Isso significa que os benefícios de um melhor ambiente econômico por parte das prefeituras do estado do Piauí não se distribuíram de forma equitativa.

Ao longo do período, a CP1 teve um crescimento da receita corrente per capita menor que as demais classes populacionais. Em 2003, a média per capita na CP1 era mais de duas vezes maior que na CP4 ou CP5, mas em 2012 a diferença diminuiu. Apesar de começar a série histórica com valores médios per capita maiores, os municípios menores foram perdendo o fôlego, tendo um crescimento per capita menor que os municípios maiores. Cabe ressaltar que, em geral, são também os municípios menores que apresentam maiores dificuldades em implementar políticas públicas.

Tabela 3 - Evolução nominal do investimento na FDL dos municípios do Piauí de 2003 a 2012 (por 1.000.000).

\begin{tabular}{lccccccccccc}
\hline CP & $\mathbf{2 0 0 3}$ & $\mathbf{2 0 0 4}$ & $\mathbf{2 0 0 5}$ & $\mathbf{2 0 0 6}$ & $\mathbf{2 0 0 7}$ & $\mathbf{2 0 0 8}$ & $\mathbf{2 0 0 9}$ & $\mathbf{2 0 1 0}$ & $\mathbf{2 0 1 1}$ & $\mathbf{2 0 1 2}$ & Var. $\%$ \\
\hline CP1 & 0,90 & 0,62 & 0,94 & 1,61 & 2,74 & 3,57 & 2,63 & 2,49 & 2,89 & 2,97 & $\mathbf{2 3 0 , 7}$ \\
CP2 & 0,84 & 0,91 & 1,36 & 2,79 & 2,66 & 5,30 & 3,65 & 2,91 & 3,05 & 5,00 & $\mathbf{4 9 1 , 7 7}$ \\
CP3 & 1,23 & 1,78 & 1,04 & 1,99 & 2,91 & 3,52 & 2,05 & 2,63 & 3,42 & 4,13 & $\mathbf{2 3 6 , 2 6}$ \\
CP4 & 0,86 & 0,61 & 0,88 & 2,12 & 2,64 & 3,51 & 3,53 & 4,08 & 4,02 & 2,47 & $\mathbf{1 8 6 , 7 4}$ \\
CP5 & 2,37 & 1,12 & 3,03 & 3,23 & 6,96 & 7,81 & 6,72 & 7,31 & 5,23 & 10,33 & $\mathbf{3 3 5 , 4 9}$ \\
Total & 6,21 & 5,04 & 7,25 & 11,74 & 17,90 & 23,71 & 18,58 & 19,41 & 18,61 & 24,90 & $\mathbf{3 0 1 , 2 8}$ \\
\hline
\end{tabular}

Fonte: Dados da pesquisa. 
A Tabela 3 indica que os municípios tiveram um comportamento bastante ativo no que diz respeito à implementação de políticas públicas de esporte e de lazer. Em todas as classes populacionais houve crescimento nominal do investimento. No entanto, chama atenção o fato da variação não ter vetor para o crescimento conforme classe populacional. O pior desempenho foi da CP4, com aumento de 186,74\% e o melhor foi da CP2, com crescimento de $491,77 \%$.

Quando se dialoga com a tabela 1, é possível identificar que apenas na CP3 e CP4 o crescimento percentual da receita corrente no período foi superior ao crescimento do investimento nominal na FDL. Nas outras classes populacionais o crescimento no investimento na FDL cresceu acima da receita corrente. O destaque fica para CP2 que teve mais que o dobro da variação da receita, de 220,20\%, no investimento na FDL, que cresceu 491,77\%.

Em linhas gerais duas, questões aparecem: a) em todas as classes populacionais houve crescimento da despesa na FDL no período de 10 anos. Isso significa que os prefeitos foram estimulados a aumentarem os recursos para as políticas públicas de esporte e de lazer; b) exceto CP3 e CP4, nas outras classes populacionais o crescimento do investimento nas políticas públicas de esporte e de lazer se deu acima da variação da receita corrente. Ou seja, tem crescido exponencialmente os investimentos dos municípios nas políticas públicas de esporte e lazer, que por vezes extrapola o aumento observado nas receitas correntes. De maneira geral, os gestores municipais têm contribuído para o fortalecimento da agenda esportiva e do lazer no estado do Piauí, aumentando os recursos destinados às políticas públicas de esporte e lazer.

Tabela 4 - Evolução do investimento médio per capita na FDL dos municípios do Piauí de 2003 a 2012 (por 1.000)

\begin{tabular}{lccccccccccc}
\hline CP & $\mathbf{2 0 0 3}$ & $\mathbf{2 0 0 4}$ & $\mathbf{2 0 0 5}$ & $\mathbf{2 0 0 6}$ & $\mathbf{2 0 0 7}$ & $\mathbf{2 0 0 8}$ & $\mathbf{2 0 0 9}$ & $\mathbf{2 0 1 0}$ & $\mathbf{2 0 1 1}$ & $\mathbf{2 0 1 2}$ & Var.\% \\
\hline CP1 & 3,72 & 2,81 & 3,82 & 5,88 & 11,80 & 16,01 & 11,67 & 9,65 & 12,17 & 12,87 & $\mathbf{2 4 5 , 7 8}$ \\
CP2 & 2,11 & 2,51 & 3,37 & 5,88 & 5,62 & 10,76 & 6,81 & 6,42 & 7,31 & 12,74 & $\mathbf{5 0 5 , 3 1}$ \\
CP3 & 3,36 & 4,56 & 3,22 & 4,60 & 5,70 & 7,80 & 4,40 & 6,74 & 8,31 & 12,69 & $\mathbf{2 7 7 , 3 7}$ \\
CP4 & 2,07 & 1,76 & 2,32 & 4,53 & 5,21 & 5,81 & 6,02 & 7,39 & 7,84 & 5,58 & $\mathbf{1 6 9 , 8 9}$ \\
CP5 & 2,07 & 1,63 & 2,37 & 2,67 & 6,12 & 8,01 & 6,84 & 6,85 & 7,06 & 8,32 & $\mathbf{3 0 1 , 8 4}$ \\
\hline
\end{tabular}

Fonte: Dados da pesquisa.

O investimento per capita na FDL também cresceu no período, como pode ser observado na tabela 4. Observa-se que o comportamento dos gestores durante o período aqui analisado levou as três primeiras classes populacionais, cidades até 20.000 habitantes, a terem o mesmo padrão de investimento per capita (recursos médios em torno dos R\$ $12,00)$ no ano de 2012. A CP2, por ter uma base inicial menor ( $\$ 2,11)$, teve que fazer um incremento robusto nos investimentos. Isso acabou colocando a CP2 na ponta da variação per capita $(505,31 \%)$. Observa-se ainda que apenas na CP4 a variação foi mais tímida $(169,86 \%)$.

Somente nas duas primeiras classes populacionais o crescimento médio per capita foi superior ao crescimento médio per capita da receita. Um fator que chama atenção é o fato da CP1 ser responsável, desde 2005, pelo maior investimento per capita na FDL. Eles 
são os municípios com menor capacidade de investimento em políticas sociais, mas têm sido proativos no financiamento das políticas públicas de esporte e de lazer.

Considerando que a inflação (IPCA) acumulada no período foi de 76,61\% e do PIB foi de $173,84 \%$ no período, a preços correntes, os investimentos na FDL incrementaram em muito as políticas públicas de esporte e de lazer, a despeito da ausência do financiamento municipal no debate acadêmico. Não só os municípios têm sido muito ativos nas políticas de esporte e lazer, como são os principais financiadores na federação brasileira (BANCO CENTRAL, 2016; IBGE, 2016).

\section{CONCLUSÃO}

A $1^{\text {a }}$ Conferência Nacional de Esporte (MINISTÉRIO DO ESPORTE, 2004) indicou como primeira diretriz: "Política esportiva e de lazer descentralizada". Logo em seguida, apontou como objetivo: "Implementar a descentralização da gestão das políticas públicas de esporte e lazer". Em 2002, antes do início do governo Lula, a participação dos municípios no investimento no esporte e no lazer já era elevada, sendo que $78,64 \%(n=4.377)$ dos municípios já faziam algum tipo de investimento na FDL. Portanto, o que segue nos dez anos seguintes é a continuidade de um processo de responsabilização dos municípios com essa agenda, apesar de todo um esforço do governo federal em promover políticas esportivas e de lazer por meio do Ministério do Esporte

Como pode ser observado ao longo do trabalho, os municípios do Piauí tiveram crescimento em suas receitas correntes, nominal e per capita. No entanto, crescimento da receita não leva, necessariamente, ao crescimento nos mesmos índices das despesas, tendo em vista que os recursos são sempre escassos e disputados. Mas, o que se percebeu no estudo, de maneira geral, foi que a FDL teve crescimento importante do ponto de vista nominal e quando comparado com a receita. O mesmo ocorreu com o investimento per capita. Ou seja, há um ambiente muito propício a garantir investimentos no esporte e no lazer no âmbito municipal.

Frente à produção científico/acadêmica da área, que pouco se dedicou a estudos abrangentes sobre o financiamento público municipal para o esporte e lazer, observar um quadro, especificamente no estado do Piauí, por meio dos dados apresentados, onde se evidencia um forte incremento nos valores investidos pelos municípios no esporte e lazer, nos faz descontruir alguns argumentos de que os municípios não vêm colaborando com o desenvolvimento do esporte e lazer no país. Além disso, inicia-se uma agenda de pesquisa, que se pretende expandir a outros estados e municípios brasileiros, a fim de desvelar, com base em dados públicos, o comportamento do orçamento público brasileiro para o esporte e lazer.

A grande questão que se coloca é no que diz respeito à qualidade desse investimento. Nesse sentido, estudos que busquem descobrir como o investimento foi dividido entre as subfunções da FDL podem ser caminhos futuros a serem seguidos. A agenda de pesquisa municipalista sobre financiamento ainda está em dívida com os estudos de políticas 
públicas de esporte e de lazer. Sem sua adequada compreensão não é possível averiguar, com precisão, o lugar dessas políticas no financiamento do esporte e do lazer no Brasil.

\section{REFERÊNCIAS}

AFONSO, José Roberto. Brasil: Descentralização Fiscal e Avanços das Políticas Sociais. In: Seminario Regional De Política Fiscal, 2003, Santiado. Anais... . Santiado: Cepal, 2003. p. 1 - 23. Disponível em: < https://www.cepal.org/ilpes/noticias/paginas/2/11542/ JRobertoAfonso.pdf>. Acesso em: 24 abr. 2018.

AFONSO, José Roberto et al. Municípios, Arrecadação e Administração Tributária: Quebrando Tabus. Revista do BNDS, Brasília, v. 10, p.1-37, dez. 1998. Disponível em: < https://www.bndes.gov.br/SiteBNDES/export/sites/default/bndes_pt/Galerias/ Arquivos/conhecimento/revista/rev1001.pdf > . Acesso em: 24 abr. 2018.

ALMEIDA, Bárbara Schausteck de; MARCHI JÚNIOR, Wanderley. O financiamento dos programas Federais de esporte e lazer no Brasil (2004 a 2008). Movimento, Porto Alegre, v. 16, n. 4, p.73-92, dez. 2010. Disponível em: < http://www.seer.ufrgs.br/index.php/ Movimento/article/view/13103/10845>. Acesso em: 24 abr. 2018.

ATHAYDE, Pedro; MASCARENHAS, Fernando; SALVADOR, Evilásio. Primeiras aproximações de uma análise do financiamento da política nacional de esporte e lazer no Governo Lula. Revista Brasileira de Ciências do Esporte, [s.I.], v. 37, n. 1, p.2-10, jan. 2015. Elsevier BV. http://dx.doi.org/10.1016/j.rbce.2013.09.002. Disponível em: < http://revista.cbce. org.br/index.php/RBCE/article/view/1556/999 > . Acesso em: 24 abr. 2015.

BOVO, José Murari. Gastos sociais dos municípios e desequilíbrio financeiro. Revista de Administração Pública, Rio de Janeiro, v. 35, n. 1, p.94-117, 2001. Disponível em: < http://bibliotecadigital.fgv.br/ojs/index.php/rap/article/view/6363/4948 > . Acesso em: 24 abr. 2018.

BRASIL. BANCO CENTRAL. Banco Central do Brasil. 2016. Disponível em: < https:// www.bcb.gov.br/pt-br/\#!/home>. Acesso em: 24 abr. 2018.

BRASIL. Constituição (1988). Constituição da República Federativa do Brasil, de 5 de outubro de 1988. Constituição da República Federativa do Brasil de 1988. Brasília, 5 out. 1988. Disponível em: < http://www.planalto.gov.br/ccivil_03/constituicao/ constituicaocompilado.htm >. Acesso em: 24 abr. 2018.

BRASIL. IBGE. Instituto Brasileiro de Geografia e Estatística. 2016. Disponível em: < http:// www.ibge.gov.br/home/>. Acesso em: 24 abr. 2018.

BRASIL. MINISTÉRIO DO ESPORTE. I Conferência Nacional do Esporte: esporte, lazer e desenvolvimento humano: documento final. Brasília: Ministério do Esporte, 2004. 65 p.

BRASIL. MINISTÉRIO DO ESPORTE. II Conferência Nacional do Esporte: documento final. Brasília: Ministério do Esporte, 2006. 8 p.

BRASIL. MINISTÉRIO DO ESPORTE. Programa Segundo Tempo. 2015. Disponível em: < http://www.esporte.gov.br/index.php/institucional/esporte-educacao-lazer-e-inclusaosocial/segundo-tempo >. Acesso em: 24 abr. 2018.

BRASIL. TESOURO NACIONAL. Sistema de Informações Contábeis e Fiscais do Setor Público Brasileiro - Siconfi. 2016. Disponível em: < https://siconfi.tesouro.gov.br/ siconfi/pages/publi >. Acesso em: 24 abr. 2018. 
BREMAEKER, Francois E. J. de. Perfil das receitas municipais. Revista de Administração Municipal, Rio de Janeiro, v. 41, n. 213, p.75-88, out. 1994. Disponível em: < http:// lam.ibam.org.br/revista_detalhe.asp?idr $=119>$. Acesso em: 24 abr. 2018.

CASTRO, Suélen Barboza Eiras de. Políticas públicas para o esporte e lazer e o ciclo orçamentário brasileiro (2004-2011): prioridades e distribuição de recursos durante os processos de elaboração e execução orçamentária. 2016. 382 f. Tese (Doutorado) - Curso de Educação Física, Programa de Pós-graduação em Educação Física, Universidade Federal do Paraná, Curitiba, 2016. Disponível em: < https://acervodigital. ufpr.br/bitstream/handle/1884/43215/R - T - SUELEN BARBOZA EIRAS DE CASTRO. pdf? sequence $=3$ \&isAllowed $=y>$. Acesso em: 24 abr. 2018.

FIGUERÔA, Katiuscia Mello et al. Planejamento, ações e financiamento para o esporte em tempos de megaeventos. Motrivivência, [s.I.], v. 26, n. 42, p.55-71, 16 jun. 2014. Universidade Federal de Santa Catarina (UFSC). http://dx.doi.org/10.5007/2175-8042.2014v26n42p55. Disponível em: <https://periodicos.ufsc.br/index.php/motrivivencia/article/view/21758042.2014v26n42p55/27266>. Acesso em: 24 abr. 2018.

GALINDO, Alexandre Gomes. Esporte e Lazer Municipal: Reflexões sobre as Bases do Planejamento e Gestão Pública. Revista do Plano Diretor Participativo do Município de Santana-AP, Santana, v. 1, n. 1, p.49-62, out. 2005. Disponível em: < http://www. ceap.br/artigos/ART27082009163226.pdf > . Acesso em: 24 abr. 2018.

GOMES, Gustavo Maia; DOWELL, Maria Cristina Mac. Descentralização Política, Federalismo Fiscal e Criação de Municípios: O que é Mau para o Econômico nem sempre é Bom para o Social. Textos Para Discussão Ipea, Brasília, n. 706, p.1-27, fev. 2000. Disponível em: < http://www.ipea.gov.br/portal/images/stories/PDFs/TDs/ td_0706.pdf >. Acesso em: 24 abr. 2018.

LINHĀAES, Meily Assbú. A trajetória política do esporte no Brasil: interesses envolvidos, setores excluídos. 1996. 221 f. Dissertação (Mestrado) - Curso de Ciência Política, Faculdade de Filosofia e Ciências Humanas, Universidade Federal de Minas Gerais, Belo Horizonte, 1996. Disponível em: < http://cev.org.br/arquivo/biblioteca/4019029. pdf >. Acesso em: 24 abr. 2018.

MENEZES, Vilde Gomes de; OLIVEIRA, Aurenéa Maria de; SOUZA, Edílson Fernandes de. Gestão desportiva e política públicana região metropolitana de Recife. Revista Brasileira de Educação Física e Esporte, São Paulo, v. 26, n. 2, p.219-230, jun. 2012. Disponível em: < http://www.scielo.br/pdf/rbefe/v26n2/05.pdf>. Acesso em: 24 abr. 2018.

MEZZADRI, Fernando Marinho et al. Políticas públicas para o esporte e lazer nas cidades do estado do Paraná. In: MEZZADRI, Fernando Marinho; CAVICHIOLLI, Fernando Renato; SOUZA, Doralice Lange de (Org.). Esporte e lazer: subsídios para o desenvolvimento e a gestão de políticas públicas. Jundiaí: Fontoura, 2006. p. 43-60.

MOTTA, Ronaldo Seroa da; MOREIRA, Ajax. Eficiência na gestão municipal no Brasil. Textos Para Discussão Ipea, Rio de Janeiro, n. 1301, p.1-25, set. 2007. Disponível em: < http://www.ipea.gov.br/portal/images/stories/PDFs/TDs/td_1301.pdf>. Acesso em: 24 abr. 2018.

REZENDE, Amaury José; SLOMSKI, Valmor; CORRAR, Luiz João. A gestão pública municipal e a eficiência dos gastos públicos: uma investigação empírica entre as políticas públicas e o índice de desenvolvimento humano (IDH) dos municípios do estado de São Paulo. Revista Universal Contábil, Blumenau, v. 1, n. 1, p.24-40, abr. 
2005. Disponível em: < http://proxy.furb.br/ojs/index.php/universocontabil/article/ view/75 > . Acesso em: 24 abr. 2018.

SILVA, Marcelo Moraes e et al. El panorama de las políticas públicas del deporte en Brasil. Observatorio del Deporte, Santiago, v. 2, n. 2, p.163-188, jun. 2016. Disponível em: $<$ https://www.researchgate.net/publication/307881574_EL_PANORAMA_DE_LAS POLITICAS_PUBLICAS_DEL_DEPORTE_EN_BRASIL>. Acesso em: 24 abr. 2018.

SILVA, Temistocles Damasceno; COUTO, Ana Marcela Santos do; SANTOS, Mario Lucas Alves dos. Análise da estrutura administrativa e financeira do esporte no município de Ipiaú-BA. Podium Sport, Leisure And Tourism Review, São Paulo, v. 3, n. 3, p.77-87, dez. 2014. Disponível em: < http://www.podiumreview.org.br/ojs/index.php/rgesporte/ article/view/104>. Acesso em: 24 abr. 2018.

SOUZA NETO, Marina Silva; SANTOS, Edmilson Santos dos; STAREPRAVO, Fernando Augusto. Programa Segundo Tempo e o Vazio Assistencial na Região Nordeste. Movimento, Porto Alegre, v. 21, n. 3, p.759-771, maio 2015. Disponível em: < http:// www.seer.ufrgs.br/index.php/Movimento/article/view/50648/39202 > . Acesso em: 24 abr. 2018.

STAREPRAVO, Fernando Augusto. Esporte, Política e Ciência: a produção científica sobre políticas públicas de esporte e lazer no Brasil. Curitiba: CRV, 2013. 164 p.

STAREPRAVO, Fernando Augusto. Políticas públicas de esporte e lazer no Brasil: aproximações, intersecções, rupturas e distanciamentos entre os subcampos político/ burocrático e científico/acadêmico. 2011. 422 f. Tese (Doutorado) - Curso de Educação Física, Departamento de Educação Física, Universidade Federal do Paraná, Curitiba, 2011. Disponível em: < https://acervodigital.ufpr.br/bitstream/handle/1884/26132/ POLITICAS + PUBLICAS + DE + ESPORTE +E + LAZER + NO + BRASIL.pdf;jsessionid $=$ F6BF79964F7C9E1C7B707AFCE8B0A577? sequence $=1$ >. Acesso em: 24 abr. 2018. TEIXEIRA, Marcelo Resende; MATIAS, Wagner Barbosa; MASCARENHAS, Fernando. O financiamento do esporte olímpico no Brasil: Uma análise do ciclo de Londres (20092012). Revista de Ciencias Sociales, Tarapacá, p.86-110, dez. 2013. Disponível em: <http://www.redalyc.org/pdf/708/70829847006.pdf>. Acesso em: 24 abr. 2018.

VERONEZ, Luiz Fernando Camargo. Quando o Estado joga a favor do privado: as políticas de esporte após a Constituição Federal de 1988. 2005. 386 f. Tese (Doutorado) Curso de Educação Física, Faculdade de Educação Física, Universidade Estadual de Campinas, Campinas, 2005. Disponível em: < http://repositorio.unicamp.br/bitstream/ REPOSIP/275418/1/Veronez_LuizFernandoCamargo_D.pdf > . Acesso em: 24 abr. 2018. 